\title{
How to Influence Users' Willingness to Explore the Use of Sports and Fitness Apps in China
}

\author{
$\mathrm{Lu} \mathrm{Suo}^{1}$ \\ ${ }^{1}$ Stamford International University, Bangkok, Thailand \\ Correspondence: Lu Suo, Stamford International University, Bangkok, Thailand. E-mail: 316346676@qq.com
}

Received: November 14, 2021

Accepted: December 11, 2021

Online Published: December 30, 2021

doi:10.5539/ass.v18n1p7

URL: https://doi.org/10.5539/ass.v18n1p7

\begin{abstract}
The aim of this paper is to investigate how inertia affects users' willingness to explore the use of sports and fitness apps under the influence of status quo bias, and to explore the role of health goals in the process of exploring use based on goal setting theory. The population in this research is Chinese users who have already installed or used a sports and fitness app on their mobile device. Through an online survey technique, we collected 449 valid questionnaires by convenience sampling method. The results confirm that inertia negatively influences the users' willingness to explore the use of sports and fitness apps and that inertia negatively influences perceived need, which, in turn, reduces the willingness to explore the use of sports and fitness apps; Furthermore, this study also verified health goal positive moderate the relationship between inertia and perceived need, as well as the relationship inertia and users' willingness to explore the use of sports and fitness apps, revealing that health goals can effectively adjust for the effects of status quo bias in mobile fitness exercise. This study provides useful suggestions for the development and operation of sports and fitness app enterprises to help them make suitable marketing strategies according to users' needs, thus promoting the long-term development of sports and fitness app enterprises.
\end{abstract}

Keywords: China, Health goal, Inertia, Perceived need, Sports and fitness apps, Willingness to use

\section{Introduction}

Health is a basic human need, and everyone needs it. At the end of August 2016, China held the National Conference on Health and promulgated the "Healthy China 2030" Plan, which incorporated the "Healthy China 2030 Plan" into the national development strategy to promote the construction of a healthy China and improve the overall health of the people ( $\mathrm{Li} \& \mathrm{Li}$, 2017). In December 2017, the National Health Planning Commission released the "China Family Health Big Data Report (2017)", which uses a big data system to interpret the health status of families, showing that China's national awareness of healthy living, active prevention and family health management has improved. However, the health situation of China's residents is not optimistic, mainly manifesting itself in the spread of diseases of the elderly in the traditional sense, such as hypertension, to younger groups, the decline in the health status of white-collar workers, the prominence of occupational diseases and the increase in chronic diseases, which are closely related to the habits and lifestyles of residents (Li, 2017). And regular exercise and fitness and other activities could effectively prevent the occurrence of chronic diseases such as coronary heart disease, resist the onslaught of disease, enhance people's physical fitness and improve people's health (Guo et al., 2017). Therefore, the residents' health also needs each of them to establish the health concept of preventing diseases before they occur and pay attention to their own exercise and fitness behavior in daily life, so as to improve their own health.

Currently, society is in the era of continuous and stable development of mobile Internet. China Business Intelligence shows that at the December of 2020, the number of mobile internet users in China has reached 986 million, an increase of 88.85 million from March 2020, accounting for $99.7 \%$ of the overall internet users (people.cn). Moreover, with the rapid development of mobile Internet technology, mobile apps are flourishing, and the app fields are becoming more and more extensive and diverse. As of the end of December 2020, 3.45 million mobile apps were monitored in the Chinese market (people.cn). At present, the use of mobile apps has become an indispensable part of people's daily life and one of the common ways to deal with things. Therefore, it is of great theoretical significance and practical value to focus on users' fitness exercise by using sports and fitness apps in the mobile Internet environment to effectively enhance national health in China. 
Sports and fitness apps belong to the sports and fitness category of mobile apps, which provide information and services such as exercise records, sports and fitness courses, exercise plans, and exercise guidance. In recent years, sports and fitness apps have been developing rapidly, and the number of users is growing fast with good momentum. The TOP1000 ranking of mobile apps in July 2020 released by Eview shows that the better-ranked sports and fitness apps, Keep with 28.779 million monthly active users, ranked 120th, and Yodo Run with 10.52 million monthly active users, ranked 242nd; but WeChat application with 994.039 million monthly active users topped the list (Analysys, 2020). Therefore, the number of monthly active users of these fitness apps is still quite low compared to mobile apps such as WeChat and Alipay. Besides, the continuous usage rate of sports and fitness apps is still relatively low, and they cannot give full play to the feature of sports and fitness apps without time and space limitation, so that users can widely and continuously carry out mobile fitness exercise. This limits the long-term development of sports and fitness apps companies. Furthermore, China's sports and fitness apps only started to enter the mobile app market in 2014-2015, and the products are still in the stage of development and gradual maturity. Because sports and fitness apps in China are all mobile apps with less active users, scholars previously neglected the in-depth research on sports and fitness apps. Although some scholars have conducted some research on sports and fitness apps, mainly focusing on the content and characteristics of sports and fitness apps, conducting research from rational behavior perspective, or using experimental methods to conduct relevant research on sports and fitness apps use (Park, Yoo, Kim, \& Lee, 2018; Yuan, Ma, Kanthawala, \& Peng, 2015), however, the existing studies have not explored users' usage behavior of sports and fitness apps in depth and systematically from the perspective of health goals.

In order to solve the problems in reality and the gaps and deficiencies in theoretical research, this paper will start from the perspective of health goals, reveal the influence process of inertia on the willingness to explore the use of sports and fitness apps through the study of the willingness to explore the use of sports and fitness apps at the stage of users' initial use of sports and fitness apps, and discover the role of health goals in the willingness to explore the use of sports and fitness apps, so as to explain the reasons why users do not use sports and fitness apps and then find the factors that motivate users to actively use sports and fitness apps. The purpose of this study is to examine the exploratory use behavior of sports and fitness apps at the initial stage when users have not fully accepted and used sports and fitness apps, to motivate users to actively use sports and fitness apps for health improvement, and to promote the wider use and development of sports and fitness apps.

\section{Literature Reviews}

\subsection{Sports and Fitness Apps}

Sports and fitness apps are a category of mobile apps that provide information and services related to sports and fitness, with clear and rich sports and fitness functions, such as running, yoga, strength exercise, etc. (Angosto, Garcia-Fernandez, Valantine, \& Grimaldi-Puyana, 2020) It can provide personalized sports and fitness programs or plans based on the user's gender, sports preferences, etc., enabling users to perform appropriate sports and fitness exercises in appropriate settings (e.g. home, community square, etc.) through fitness videos, voice, etc. At the same time, it offers records of the number of times a user works out, the time spent, and the fitness status after the user has performed a fitness exercise so that the user's fitness exercise could be tracked. Moreover, some apps also provide one-to-one coaching services to guide users to perform more suitable fitness exercises according to their personal conditions (Park et al., 2018). This study focuses on sports and fitness apps installed on smartphones, which provide different degrees of fitness-related functions and also provide user health level detection, exercise and fitness planning, guidance, and recording, which are more comprehensive ways to assist users in exercising and fitness.

\subsection{Goal-Setting Theory}

Goal-setting theory asserts that goal-oriented behavior has three properties: (1) self-generation, i.e., the organism's energy source is intact; (2) value significance: i.e., the action is not only possible but necessary for the organism's survival; and (3) goal causation: i.e., the goal causes the outcome. The theory articulates a simple and straightforward explanation for why some people perform better behavior than others, and the reason for this is that they set different goals for their performance (Latham \& Locke, 1991). In other words, conscious people behave purposefully, and individual goals govern human behavior. Locke and Latham (1991) define goals simply as the degree of desire or the purpose of action (Latham \& Locke, 1991; Lee, Locke, \& Phan, 1997). Fort, Jacquet, and Leroy (2011) determine personal goals as an individual's desire to engage in a particular behavior or produce a particular outcome. Overall, a goal is a valuable outcome that people want to achieve or behavior that they want to perform (Bagozzi \& Edwards, 1998).

Once goals are set, they guide people to take action to achieve them. In the process of achieving goals, goals 
enable people to manage their behavior and motivate them to put in the continuous effort and persist in the assigned task until the goal is achieved (Locke, Frederick, Lee, \& Bobko, 1984). Even with occasional interruptions, goals get people back into action and persist in a lasting way (Papies, 2016). Goals have a significant influence on human behavior, and individuals with goals have better behavioral performance than those without goals (Locke et al., 1984). Previous literature has also noted that in goal setting, people may have different goals, the degree of goal setting may vary, and it is valuable to test the impact of these goals on behavior (Downes, Kristof-Brown, Judge, \& Darnold, 2017). After a user sets a goal, the user consciously thinks about what methods and actions to take to achieve the goal, and in the process of achieving the goal, the user's own abilities have an important influence on the achievement of the goal (Phillips, \& Gully, 1997; Vance \& Colella, 1990). Although competence is an inherent and essential characteristic of an individual, reflecting the actual level of ability to solve a problem, it is also malleable and can be developed and improved through learning and effort, as individuals develop new skills and acquire new knowledge. The level of competence determines the extent to which goals are achieved, and performance outcomes (Bell \& Kozlowski, 2002). Previous research has suggested that the combination of factors such as goals and competencies have a greater impact on performance than goals themselves (Locke et al., 1984). Locke et al. (1984) verified that goals, competence, past training ability, self-efficacy and the use of strategies are effective in promoting performance. In the health domain, goals are often used as a self-management tool to make people aware of health needs through set goals and to intervene in their choice of behavior through explicit goals, thus effectively promoting the development of healthy behaviors (Plaete, Bourdeaudhuij, Verloigne, \& Crombez, 2016). It has been shown that goals have a significant contribution to health-related behavior change, such as weight management, physical activity and healthy eating (Locke et al., 1984; Bagozzi \& Edwards, 1998; Fort et al., 2011). Goal setting has become a part of health education as a way to promote healthy behaviors (Strecher, Seijts, Kok, Latham, Glasgow, DeVellis, Meertens, \& Bulger, 1995). This study will explore the considerable role of health goals in the use of sports and fitness apps, using goal-setting theory as the main theoretical basis.

\subsection{Status Quo Bias Theory}

Samuelson and Zeckhauser (1988) point out that status quo bias is a quite common phenomenon in practical decision making. Faced with a new decision, the decision-maker will prefer to do nothing or to keep the current state or the previous decision. Status quo bias may be related to three reasons: first, the presence of transfer costs or uncertainty when making rational decisions; second, the presence of false perceptions in cognition; and third, the psychological commitment that comes from false perceptions of input costs, avoidance of causing regret, and trends in consistency. Research based on status quo bias theory could explain, at a theoretical level, why individuals are more likely to maintain status quo choices and resist new ones (Samuelson \& Zeckhauser, 1988; Kim \& Kankanhalli, 2009). By integrating technology theory and status quo bias theory, Kim and Kankanhalli (2009) explained that users would first choose against using a new information system and be reluctant to make a new assessment of the changes it would bring. In their study, Kim and Kankanhalli (2009) chose the factors of net benefits, switching costs, uncertainty costs, loss aversion, sunk costs, social influence, and perceived control to represent the hindering factors present in status quo bias in terms of three aspects: rational decision making, cognitive bias, and psychological commitment. In other studies, researchers have also chosen uncertainty and resource redistribution as hindering factors (Zhang, 2014; Kim \& Kankanhalli 2009). In contrast to these studies, Polites and Karahanna (2012) used inertia as a variable to measure the overall status quo theory of deviance, noting that inertia responds to an individual's tendency to remain in the current state even when better options or incentives prompt users to change, and they verified that habitual use of the current system and switching costs, among other things, promoted user inertia, which in turn influenced users' use of the new system. Inertia is often used to reflect status quo bias in studies of status quo bias theory (Sun, Liu, Chen, Wu, Shen, \& Zhang, 2017; Wang, Wang, \& Lin, 2018; Polites \& Karahanna, 2012). Based on the push-pull mooring framework, Sun, et al. (2017) proposed that inertia is a vital influencing factor in the anchor effect when studying users' willingness to switch in mobile instant messaging app scenarios, verifying that emotional commitment, switching costs, and habit are the main causes of inertia, which in turn influences users' switching behavior. Wang et al. (2018) explored the role of inertia in influencing the willingness to upgrade next-generation information systems by integrating the status quo bias theory and Warshaw's purchase intention model. In their study, Wang et al. (2018) used inertia as a general performance outcome of status quo bias and verified that inertia has different effects such as direct, mediating, and moderating effects. These findings suggest that inertia can reflect the status quo deviance state of users.

Based on existing research on inertia, this study considers the use of inertia to represent the current state of users in order to explain the reluctance of users to try using exercise and fitness apps, with the aim of exploring the 
role of inertia as a deterrent and the process of influence that affects the exploration of the use of exercise and fitness apps. In this study, inertia is defined as an individual's attachment to, and maintenance of, an existing or habitual pattern of behavior, even when there is a better alternative or incentive to prompt the individual to change (Polites \& Karahanna, 2012).

\subsection{Health Goal}

Health goals are intrinsic desires that people want to achieve in relation to their health (Lee, Locke, \& Phan, 1997). Set health goals consciously evoke intrinsic motivation and inspire people to put effort into improving their health, and health goals can be effective in improving people's health status. Previous literature has examined the relationship between health goals and health behaviors, such as Papies (2016) who presupposes health goals as situational intervention tools that enable people to unconsciously respond to this specific cue message in a health-related context, thereby effectively promoting health behaviors. In the areas of physical activity, healthy eating, and weight management, research has shown that health goals have a positive motivational effect on behavior and are effective in improving human health behavior (Latham \& Locke, 2006; Sebire, Standage, \& Vansteenkiste, 2011). Sebire et al. (2011) have validated the indirect effects of intrinsic and extrinsic goals regarding exercise on physical activity behavior. Moreover, it is only when people form clearer health goals that they will set specific plans and take a series of actions to achieve their health goals and thus realize their health needs. Considering the important role of health goals in influencing changes in people's health behaviors, this study introduces the health goals construct to explore the influence of health goals on mobile fitness users' usage behaviors. In the mobile Internet environment, exercise and fitness apps, although dedicated to improving people's health, have not attracted widespread attention and use. Only when users have health needs or desires and identify their health goals are they likely to try to use sports and fitness apps, such as health information querying, health knowledge acquisition, or functional use of sports and fitness apps; users are likely to manage their mobile fitness behaviors with health goals in mind and thus adhere to their mobile fitness exercise. In this study, health goals are defined as the desire of individuals to exercise through the use of sports and fitness apps with the aim of obtaining healthy outcomes (Fort et al., 2011).

\subsection{Perceived Needs}

Health needs are basic human needs, and the intrinsic nature of human needs leads people to live healthier and happier lives (Maslow, 1968). Some studies have argued that there can be subtle differences between an individual's actual state and their needs for a particular need or desire, hence the need for need identification (Teng, Lu, \& Yu, 2009). In line with these studies, some studies have used perceived needs as salient beliefs to predict behavior (Wang et al., 2018; Teng, Lu, \& Yu, 2009; Payne, Jones, \& Harris, 2004). For example, perceived needs are used to represent users' needs for health behaviors when describing the presence of health problems in health behavior studies, such as those on improving diet and physical activity (Payne et al., 2004; Vähäsarja et al., 2012). In information systems research, researchers have also used perceived need to predict user acceptance of information systems, or to predict use of upgraded technological systems (Teng et al., 2009; Jeong, Yoo, \& Heo, 2009). In this study, perceived need refers to the extent to which users perceive health benefits from using an exercise and fitness apps (Wang et al., 2018). In the mobile internet environment, users need to identify their health needs, clearly perceive their health desires and needs in their beliefs, form the intention to use exercise and fitness apps, and then exercise to increase their health. This study considers perceived needs as beliefs that are highly valued by mobile fitness users to predict the intention to explore the use of exercise and fitness apps and to investigate the mediating role of perceived needs in inertia and the intention to explore the use of exercise and fitness apps.

\section{Conceptual Framework and the Development of Hypothesis}

\subsection{The Relationship Between Inertia and Willingness to Explore the Use of Sports and Fitness Apps}

Research on status quo bias theory states that inertia makes users stay in their current state and are not willing to change. In the current mobile society, the use of mobile apps has become part of people's daily lives and many people are used to using the mobile apps they currently use to meet their different needs by using these mobile apps (Sun et al., 2017), such as communication, entertainment and finding information. And, they are so used to their current state that they do not consider using mobile fitness apps for exercise. Thus, although sports and fitness apps provide features and courses suitable for different users to carry out exercises (e.g., yoga courses and strength courses, etc.) and provide information useful for users to carry out fitness exercises such as fitness records, users can carry out mobile fitness exercises scientifically regardless of time and location (Guo et al., 2017). And even if users know or understand the advantages and benefits of fitness apps, they may prefer to stay in their old state rather than explore them to improve their health and achieve a healthier body. Furthermore, 
even in a traditional setting, users need to overcome their inertia in order to start exercising (Lees, Clarkr, Nigg, $\&$ Newman, 2005). Thus, it can be seen that inertia has a strong influence on human behavior.

Previous research has shown that inertia has a negative impact on the use of new IT apps (Sun et al., 2017; Wang et al., 2018; Polites \& Karahanna, 2012). Polites and Karahanna (2012) verified through empirical research that inertia has a negative impact on the willingness to use new systems such as Google Docs. Sun et al. (2017) found that inertia had a negative effect on users' willingness to switch when they moved from their current mobile instant messaging app to another mobile instant messaging app in an anchor effect. Wang et al. (2018) verified that inertia negatively influences users' willingness to upgrade to a new generation system. From this, it can be seen that inertia plays a hindering role in people's actions. Therefore, this study argues that inertia has a negative effect on the willingness to use mobile fitness exploration. That is, users' existing behavioral patterns can hinder their exploratory use of sports and fitness apps, thus preventing them from reaping the potential health benefits. Based on the above discussion, the following hypotheses are proposed in this study:

H1: Inertia negatively influences the willingness to explore the use of sports and fitness apps.

\subsection{The Relationship Between Inertia and Perceived Need}

In a mobile fitness scenario, users tend to stay in their current state due to inertia (Sun et al., 2017; Polites \& Karahanna, 2012) habitually using their usual mobile apps for daily life and work, and often neglecting to use sports and fitness apps for fitness exercises. When users are in this state of inertia, they strive to maintain it cognitively, and cognitive congruence will avoid the formation of cognitive dissonance. Cognitive dissonance is the deviation that occurs between the current state and the user's perception (Polites \& Karahanna, 2012). Thus, even though health needs are fundamental to users and sports and fitness apps have many advantages for conducting mobile fitness exercises, users in a state of inertia are often reluctant to identify their health needs and thus conduct fitness exercises. Polites and Karahanna (2012) have shown that inertia diminishes users' perceptions of new systems, such as perceived ease of use and relative advantage etc. Therefore, this study suggests that inertia may reduce users' perceptions of their mobile fitness needs. In other words, inertia hinders mobile users from perceiving their health needs. Hence, this study proposes the following hypothesis.

$\mathrm{H} 2$ : Inertia negatively influences perceived need.

\subsection{The Relationship Between Perceived Need and Willingness to Explore the Use of Sports and Fitness Apps}

Despite the fact that health needs are intrinsic to human nature, for most people they will often neglect their health needs. It is only when people realize that they need to change their health status and achieve better health benefits that they will focus on physical activity. In a mobile fitness scenario, only when users identify their health and fitness needs will they be able to evoke their internal beliefs and thus think about how to meet their needs (Teng et al., 2009; Jeong et al., 2009). From this, users will then be willing to explore the use of the sports and fitness apps and discover the potential health benefits. As perceived needs increase, strong intrinsic beliefs enhance users' willingness to use mobile fitness. It has been shown that perceived need is an antecedent of user acceptance of using new information technologies (Wang et al., 2018; Jeong et al., 2009). For example, Jeong et al. (2009) showed that perceived need explained users' willingness to purchase mobile radio frequency services; Wang et al. (2018) verified that perceived need had a positive effect on the behavioral willingness to upgrade to a new generation system. Therefore, this study concludes that perceived demand has a positive influence on the willingness to use sports and fitness apps. Based on the above discussion, the following hypotheses are proposed in this study.

H3: Perceived need positively influences willingness to use sports and fitness apps.

\subsection{The Mediating Role of Perceived Need}

Based on the discussion of hypothesis $\mathrm{H} 2$ above, inertia keeps the mobile user in the original state and keeps the user's perception of the perceived need also in line with the current state to avoid causing cognitive dissonance (Polites \& Karahanna, 2012). In other words, inertia attenuates the user's perception of health needs. Furthermore, as discussed in hypothesis $\mathrm{H} 3$ above, when users identify a health need, they will be inclined to try to explore exercise and fitness apps, thus reaping the health benefits (Wang et al., 2018; Jeong et al., 2009). However, as perceived need decreases, weakened intrinsic beliefs do not motivate much willingness to explore the use of sports and fitness apps, resulting in lower willingness to use sports and fitness apps. Thus, inertia reduces users' perceived need and, in turn, the reduced perceived need reduces the willingness to explore the use of the sports and fitness apps. Polites et al. (2012) verified that inertia partially mediates users' willingness to use a new system through their attitudinal beliefs, such as perceived willingness and relative advantage (Polites $\&$ Karahanna, 2012). This study argues that perceived need mediates the effect of inertia on the willingness to use 
sports and fitness apps. Based on the above discussion, this study proposes the following hypotheses.

H4: Inertia influences willingness to use sports and fitness apps through perceived need.

\subsection{The Moderating Role of Health Goals}

Health goals are people's aspirations to achieve health benefits in the future (Latham \& Locke, 1991; Locke, 1996). Health goals are often effective as self-management tools to improve people's health. However, when people set goals, they consider not only what they want, but also what is possible to achieve (Bandura, \& Cervone, 1986). As a result, people set goals of varying degrees of ambition. Latham and Locke (1991) noted that people with low goals would be satisfied with the low level of performance achieved and would be more satisfied with performance above that level of performance; whereas people with high goals would be more motivated to achieve them, thereby reinforcing their actual gains and increasing their self-satisfaction. High goals are more useful than low goals in achieving both practical and psychological gains (Latham \& Locke, 1991). High goals imply that users manage their behavior with greater awareness to achieve their goals (Locke, 1996; Bandura \& Cervone, 1986). That is, in the case of high goals, a strong sense of reaching the goal is in the dominant state. In the mobile fitness scenario, inertia leads to some biases in the perceptions, intentions and behaviors of mobile app users. The high goal motivates a strong sense of self-management to achieve health goals (Latham \& Locke, 1991; Locke, 1996; Bandura \& Cervone, 1986). As a result, the dominant sense of self-management reduces the influence of inertia on mobile users' perceptions and intentions (Locke, \& Latham, 2006; Dec \& Ryan, 2000). The health goal adjusted for the effects of inertia-induced bias. Thus, a high health goal attenuates the negative effect of inertia on perceived demand and the negative effect of inertia on the willingness to explore the use of exercise and fitness apps. In addition, based on the intrinsic health desires, users set health goals and identify their health needs (Latham \& Locke, 1991). With high health goals, a strong sense of self-management is more helpful for users to identify their health needs and be willing to try to use exercise and fitness apps to achieve their health goals. Therefore, high health goals enhance the influence of perceived needs on the willingness to use exercise and fitness apps. Based on the above discussion, the following hypotheses are proposed in this study.

H5a: Health goal moderates the relationship between inertia and willingness to use the sports and fitness apps, i.e., a high health goal reduces the negative effect of inertia on willingness to use the sports and fitness apps.

H5b: Health goal moderates the relationship between inertia and perceived need, i.e., a high health goal reduces the negative effect of inertia on perceived need.

H5c: Health goal moderates the relationship between perceived need and willingness to use the sports and fitness apps, i.e., a high health goal enhances the effect of perceived need on willingness to use the sports and fitness apps.

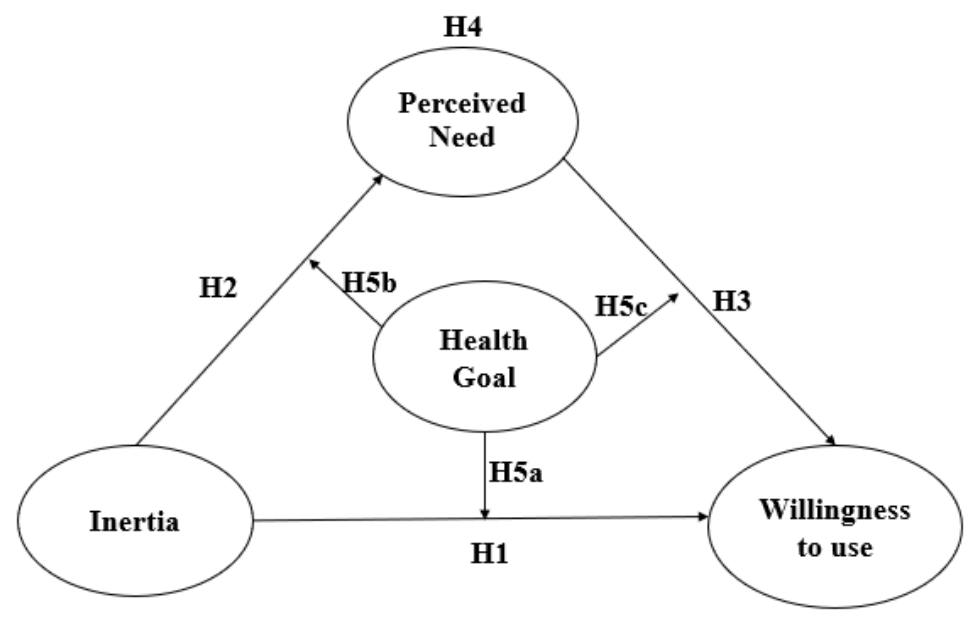

Figure 1. Conceptual Framework of This Study

\section{Methodology}

\subsection{Sample and Data Collection}

The population in this research is Chinese customers who have already installed or used a sports and fitness app 
on their mobile device (e.g., smartphone). As the size of the target population is difficult to estimate, the sample size used in the quantitative analysis will be calculated using Cochran's (1977) formula. The actual sample size is estimated to be 385 at a $95 \%$ confidence level. Through a questionnaire, this study collected data on sports and fitness app usage via an online survey technique. The online data collection technique allowed a diverse group of mobile fitness users from various parts of China to complete the survey and collect data. A total of 491 surveys were received by an internet link. Finally, there were 449 valid surveys in total after eliminating invalid questionnaires.

\subsection{Questionnaire and Measurement Scale}

The measurement scale for this study was designed on the basis of existing questionnaires and literature, with appropriate modifications and adjustments to the scale to suit this study scenario. The questionnaire was divided into three sections: basic information about the respondents, basic information about the use of the sports and fitness app, and the items measured for each variable. The variable measurement section used a five-point Likert scale with a range of options from 1 to 5: strongly disagree, disagree, neutral, agree, and strongly agree. The questionnaire was revised through pre-testing and revision, and the revised scale has 18 questions with 4 indicator measurement variables. Details of the design of the measurement items are presented in Table 1.

Table 1. Source of Measurement Item

\begin{tabular}{|c|c|c|}
\hline Variable & Measurement Items & Source \\
\hline \multirow{6}{*}{$\begin{array}{l}\text { Inertia } \\
\text { (In) }\end{array}$} & I never thought of switching to a sports and fitness app. & \multirow{12}{*}{$\begin{array}{l}\text { Wang et } \\
\text { al. } \\
\text { (2018) }\end{array}$} \\
\hline & I do not care about the features of the sports and fitness apps. & \\
\hline & I am not willing to consider switching to a sports and fitness app. & \\
\hline & $\begin{array}{l}\text { I will continue with the status quo, even though I know it is a bit ineffective in } \\
\text { improving my health/being fit }\end{array}$ & \\
\hline & $\begin{array}{l}\text { I will continue with the status quo, even though I know it is not good for improving } \\
\text { health/being fit health }\end{array}$ & \\
\hline & $\begin{array}{l}\text { I will continue with the status quo, even though I know it is not the best way to } \\
\text { improve my health/fitness }\end{array}$ & \\
\hline \multirow{6}{*}{$\begin{array}{l}\text { Perceived } \\
\text { Need } \\
(\mathrm{PN})\end{array}$} & At the moment, I often need to use the sports and fitness apps & \\
\hline & The services provided by the sports and fitness apps are important to me & \\
\hline & Now I need the sports and fitness apps & \\
\hline & I really would like to use the sports and fitness app & \\
\hline & $\begin{array}{l}\text { Due to the pressure I feel from the outside world, I really would like to use the } \\
\text { sports and fitness apps }\end{array}$ & \\
\hline & Because of my own desires, I really want to use the sports and fitness apps & \\
\hline \multirow{3}{*}{$\begin{array}{l}\text { Health Goal } \\
\qquad(\mathrm{HG})\end{array}$} & My health goal is to manage my health through the use of a sports and fitness app & \multirow{3}{*}{$\begin{array}{c}\text { Lee, } \\
\text { Locke \& } \\
\text { Phan } \\
(1997)\end{array}$} \\
\hline & My health goal is to improve my health through the use of a sports and fitness app & \\
\hline & My health goal is to have a healthy body through the use of a sports and fitness app & \\
\hline \multirow{3}{*}{$\begin{array}{c}\text { Willingness } \\
\text { to Use } \\
\text { (WU) }\end{array}$} & $\begin{array}{l}\text { I intend to explore the features of the sports and fitness apps to improve health / } \\
\text { carry out fitness }\end{array}$ & \multirow{3}{*}{$\begin{array}{c}\text { Nambisan, } \\
\text { Agarwa \& } \\
\text { Tanniru } \\
\text { (1999) }\end{array}$} \\
\hline & and fitness apps to improve health/enhance fitness results & \\
\hline & $\begin{array}{l}\text { I intend to spend considerable time and effort in exploring the sports and fitness } \\
\text { apps for potential functions }\end{array}$ & \\
\hline
\end{tabular}

\section{Data Analysis and Findings}

\subsection{Descriptive Statistical Analysis}

The descriptive statistical analysis is shown in Table 2. In this survey, men accounted for 146 people and women 303 people, women use sports and fitness apps for exercise more often than men; the age of the respondents was 
177 people between 20 and 29 years old, and 198 people between 30 and 39 years old, so the number of people between 20 and 39 years old accounted for $83.52 \%$, we can see that users in this age group are the main group of sports and fitness apps. The main types of sports and fitness apps are Keep and Yodo Run, which is consistent with the monthly activity ranking of mobile apps in China in July 2020, and these two sports apps rank better and have a relatively high level of activity (Analysys, 2020); the majority respondents' experience of using sports and fitness apps is more than one year. From the results of the above descriptive statistical analysis, mobile fitness users are mainly concentrated in the youth group with certain educational backgrounds, and a large portion of users often use sports and fitness apps for fitness exercise.

Table 2. Demographic Profile of the Respondents

\begin{tabular}{cccc}
\hline & Variable & Frequency & $\%(\mathrm{n}=449)$ \\
\hline \multirow{2}{*}{ Gender } & Male & 146 & $32.52 \%$ \\
& Female & 303 & $67.48 \%$ \\
Age (years old) & Under 20 & 24 & $5.35 \%$ \\
& $20-29$ & 177 & $39.42 \%$ \\
& $30-39$ & 198 & $44.10 \%$ \\
Your Education & $40-49$ & 32 & $7.13 \%$ \\
& Above 50 & 18 & $4.01 \%$ \\
& High school & 21 & $4.68 \%$ \\
& Diploma & 59 & $13.14 \%$ \\
Time of Using Sports and & Bachelor's Degree & 284 & $63.25 \%$ \\
Fitness Apps & Master's Degree & 75 & $16.70 \%$ \\
& Doctoral Degree & 10 & $2.23 \%$ \\
& $<1$ Month & 38 & $8.46 \%$ \\
& $1-3$ Months & 67 & $14.92 \%$ \\
& $4-6$ Months & 86 & $19.15 \%$ \\
Which sports and fitness apps & $7-12$ Months & 91 & $20.27 \%$ \\
have you used? & $>1$ Year & 167 & $37.19 \%$ \\
& Keep & 184 & $40.98 \%$ \\
& Yodo Run & 156 & $34.74 \%$ \\
& Parkour & 49 & $10.91 \%$ \\
& Le Dong Li & 37 & $8.24 \%$ \\
& boobhee & 16 & $3.56 \%$ \\
& Others & $7.56 \%$ \\
\hline
\end{tabular}

\subsection{Reliability and Validity}

It was found that the Cronbach's $\alpha$ for each construct was greater than 0.7 , indicating a high reliability of our survey instrument (Nunnally, 1978). Moreover, our results showed that the factor loadings for all of the constructs exceeded 0.5, indicating that they passed the item reliability test (Hair et al., 1995). The composite reliability (CR) of all the constructs was well above the critical point of 0.7 , indicating adequate construct reliability (Fornell \& Larcker, 1981). The average extracted variance (AVE) for each construct exceeded 0.5, demonstrating convergent validity (Fornell \& Larcker, 1981). Table 3 shows that all variables in this study have good reliability and convergent validity. In Table 4, the square root of the average variance extracted (AVE) for each of the five variables on the diagonal was higher than the corresponding row and column values, indicating good discriminant validity for the scale in this study (Venkatesh \& Morris, 2003). 
Table 3. Results of Validity and Reliability Analysis

\begin{tabular}{|c|c|c|c|c|c|}
\hline Factors & Indicators & Factor Loadings & AVE & $\mathrm{CR}$ & Cronbach's Alpha \\
\hline \multirow{6}{*}{$\begin{array}{l}\text { Inertia } \\
\text { (In) }\end{array}$} & In1 & 0.802 & \multirow{6}{*}{0.626} & \multirow{6}{*}{0.895} & \multirow{6}{*}{0.894} \\
\hline & In 2 & 0.811 & & & \\
\hline & In3 & 0.796 & & & \\
\hline & In 4 & 0.815 & & & \\
\hline & In5 & 0.843 & & & \\
\hline & In6 & 0.829 & & & \\
\hline \multirow{6}{*}{$\begin{array}{l}\text { Perceived Need } \\
\qquad(\mathrm{PN})\end{array}$} & PN1 & 0.751 & \multirow{6}{*}{0.613} & \multirow{6}{*}{0.905} & \multirow{6}{*}{0.893} \\
\hline & PN2 & 0.736 & & & \\
\hline & PN3 & 0.774 & & & \\
\hline & PN4 & 0.789 & & & \\
\hline & PN5 & 0.743 & & & \\
\hline & PN6 & 0.756 & & & \\
\hline \multirow{3}{*}{$\begin{array}{l}\text { Willingness to Use } \\
\text { (WU) }\end{array}$} & WU1 & 0.846 & \multirow{3}{*}{0.679} & \multirow{3}{*}{0.894} & \multirow{3}{*}{0.889} \\
\hline & WU2 & 0.817 & & & \\
\hline & WU3 & 0.892 & & & \\
\hline \multirow{3}{*}{$\begin{array}{l}\text { Health Goal } \\
\qquad(\mathrm{HG})\end{array}$} & HG1 & 0.846 & \multirow{3}{*}{0.637} & \multirow{3}{*}{0.890} & \multirow{3}{*}{0.849} \\
\hline & HG2 & 0.829 & & & \\
\hline & HG3 & 0.868 & & & \\
\hline
\end{tabular}

Table 4. Discriminate Validity

\begin{tabular}{ccccc}
\hline Variable & In & PN & HG & WU \\
\hline In & 0.791 & & & \\
PN & -0.332 & 0.783 & & \\
HG & -0.305 & 0.625 & 0.824 & \\
WU & -0.304 & 0.657 & 0.549 & 0.798 \\
\hline
\end{tabular}

\subsection{Measurement and Structural Model Analysis}

Based on the above conceptual model, structural equation modelling was carried out using AMOS 23.0 software. Firstly, the fit of the model was validated and assessed against six key indices. The results shown in Table 4 indicate that all the indices met their thresholds, confirming a good fit of the model. The structural model was then analyzed and fitted. All values met their recommended values (Table 5); therefore, the structural equation model was acceptable.

Table 5. Fit Indices of Measurement and Structural Models

\begin{tabular}{ccccccc}
\hline Fit indices & $\chi 2 / \mathrm{df}$ & GFI & AGFI & CFI & NFI & RMSEA \\
\hline Recommended Values & $<3$ & $>0.9$ & $>0.8$ & $>0.9$ & $>0.9$ & $<0.05$ \\
Measurement Model & 1.948 & 0.904 & 0.911 & 0.922 & 0.934 & 0.048 \\
Structural Model & 1.949 & 0.905 & 0.913 & 0.922 & 0.935 & 0.047 \\
\hline
\end{tabular}

\subsection{Hypothesis Testing}

The result of hypotheses testing is shown in Table 6. From Table 6, concerning H1, users' inertia has a significant negative effect on user willingness to explore the use of sports and fitness apps $(\beta=-0.472, p<.001)$. Therefore, hypothesis $\mathrm{H} 1$ is fully supported. With regard to H2, users' inertia has a significant negative effect on users' 
perceived need $(\beta=--0.351, \mathrm{p}<.001)$. Therefore, $\mathrm{H} 2$ is supported. Regarding $\mathrm{H} 3$, we find that perceived need ( $\beta=$ $0.681, \mathrm{p}<.001)$ has a positive influence on user willingness to explore the use of sports and fitness apps. Thus, H3 is supported.

Table 6. Result of Hypothesis Test

\begin{tabular}{ccccc}
\hline Hypothesis & Path & Path Coefficient $(\beta)$ & Significance & Results \\
\hline $\mathrm{H} 1$ & $\mathrm{In} \rightarrow \mathrm{WU}$ & -.472 & $* * *$ & Supported \\
$\mathrm{H} 2$ & $\mathrm{In} \rightarrow \mathrm{PN}$ & -.351 & $* * *$ & Supported \\
$\mathrm{H} 3$ & $\mathrm{PN} \rightarrow \mathrm{WU}$ & .681 & $* * *$ & Supported \\
\hline
\end{tabular}

$* \mathrm{P}<0.05 ; * * \mathrm{P}<0.01 ; * * * \mathrm{P}<0.001$

\subsection{Mediating Effect Test}

The health goal's mediating impact is investigated using bootstrapping in this study. The bootstrapping approach assesses the significance of mediating effects by assessing whether the interval between the minimum and the maximum contains 0. Hair et al. (2017) explained that the path coefficient is significant if the "confidence interval does not contain the value 0." Table 6 summarizes the findings. It is clear that perceived need plays significant mediating effects between inertia and willingness to explore the use of the sports and fitness apps. As a result, $\mathrm{H} 4$ is supported.

Table 7. Indirect effects of the bootstrapping test

\begin{tabular}{|c|c|c|c|c|c|}
\hline \multirow{2}{*}{ Hypothesis } & \multirow{2}{*}{$\begin{array}{l}\text { Estimated } \\
\text { Value }\end{array}$} & \multicolumn{2}{|c|}{ Bias-Corrected 95\% CI } & \multirow{2}{*}{$\mathrm{p}$} & \multirow{2}{*}{$\begin{array}{c}\text { Conclusion } \\
\text { (With or without Mediating effect) }\end{array}$} \\
\hline & & Lower & Upper & & \\
\hline $\mathrm{H} 4: \mathrm{In} \rightarrow \mathrm{PN} \rightarrow \mathrm{WU}$ & -.253 & -.284 & -.158 & $* *$ & Yes \\
\hline
\end{tabular}

\subsection{Moderating Effect Test}

Before multiplying the moderating factors with the predictor variables, mean-centered indicator values are calculated to identify the moderating effects (also known as interaction terms). Ping (1995) confirmed this technique as a useful tool for evaluating route models with potential variable interactions. Table 8 , Table 9 and Table 10 shows the results of path coefficient and bootstrap t-value of interactions. As Table 8 shows, the moderating effect of health goal was confirmed. In line with our hypothesis, health goal was found to moderate the link between inertia and willingness to use in a positive way $(\beta=.176, p<.01)$. Thus, H5a was fully supported. As can be seen in Table 9, consistent with H5b, health goal was found to moderate the link between inertia and willingness to use in a positive way $(\beta=.258, p<.001)$, therefore, H5b was fully supported. From Table 10 , health goal was not found to moderate the relationship between perceived need and willingness to use $(\beta=.001, p>.05)$. Thus, H5c failed to be supported.

Table 8. Moderating Effects of Health Goal on The Relationship Between Inertia and Willingness to Use

\begin{tabular}{|c|c|c|c|c|c|c|c|}
\hline \multirow{3}{*}{ H5a } & \multirow[t]{2}{*}{ IV } & \multirow{2}{*}{ Moderator } & \multirow{2}{*}{ Interactions } & \multirow{2}{*}{$\begin{array}{c}\text { Bootstrap } \\
\text { t-value }\end{array}$} & \multirow{2}{*}{$\begin{array}{c}\text { Path } \\
\text { Coefficient } \\
(\beta)\end{array}$} & \multicolumn{2}{|c|}{$\begin{array}{c}\text { Bias-Corrected } \\
95 \% \mathrm{CI}\end{array}$} \\
\hline & & & & & & Lower & Upper \\
\hline & Inertia & Health Goal & Inertia x Health Goal & 2.081 & $0.176^{* *}$ & 0.069 & 0.276 \\
\hline
\end{tabular}

Table 9. Moderating Effects of Health Goal on The Relationship Between Inertia and Perceived Need

\begin{tabular}{|c|c|c|c|c|c|c|c|}
\hline \multirow{3}{*}{$\mathrm{H} 5 \mathrm{~b}$} & \multirow{2}{*}{ IV } & \multirow{2}{*}{ Moderator } & \multirow{2}{*}{ Interactions } & \multirow{2}{*}{$\begin{array}{c}\text { Bootstrap } \\
\text { t-value }\end{array}$} & \multirow{2}{*}{$\begin{array}{c}\text { Path } \\
\text { Coefficient } \\
(\beta)\end{array}$} & \multicolumn{2}{|c|}{$\begin{array}{c}\text { Bias-Corrected } \\
95 \% \mathrm{CI}\end{array}$} \\
\hline & & & & & & Lower & Upper \\
\hline & Inertia & Health Goal & Inertia x Health Goal & 3.957 & $0.258 * * *$ & 0.043 & 0.239 \\
\hline
\end{tabular}


Table 10. Moderating Effects of Health Goal on the Relationship Between Perceived Need and Willingness to Use

\begin{tabular}{cccccccc}
\hline \multirow{2}{*}{ H5c } & IV & Moderator & Interactions & $\begin{array}{c}\text { Bootstrap } \\
\text { t-value }\end{array}$ & $\begin{array}{c}\text { Path } \\
\text { Coefficient } \\
(\beta)\end{array}$ & \multicolumn{2}{c}{$\begin{array}{c}\text { Bias-Corrected } \\
\text { 95\% CI }\end{array}$} \\
\cline { 2 - 4 } & $\begin{array}{c}\text { Perceived } \\
\text { Need }\end{array}$ & Health Goal & $\begin{array}{c}\text { Perceived Need } \mathrm{x} \\
\text { Health Goal }\end{array}$ & 0.003 & $0.001^{\text {ns }}$ & -0.124 & 0.159 \\
\hline \multicolumn{3}{c}{$* \mathrm{P}<0.05 ; * * \mathrm{P}<0.01 ; * * * \mathrm{P}<0.001$, ns=non significance } \\
\hline
\end{tabular}

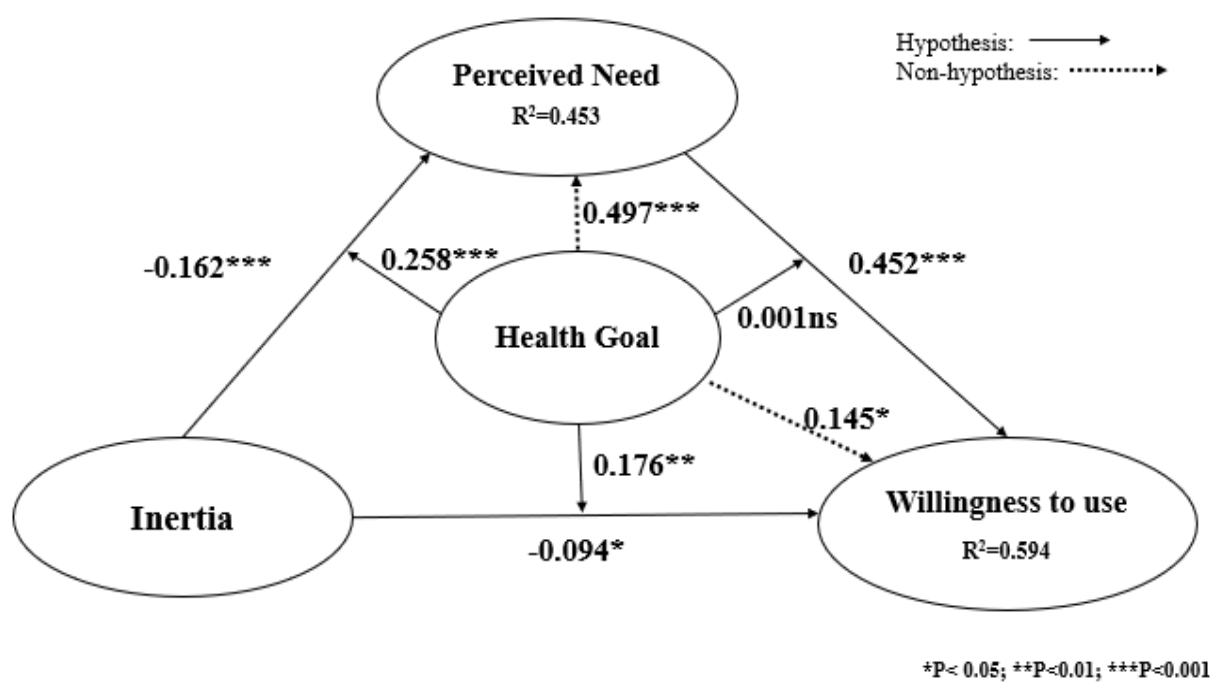

Figure 2. Results For the Moderating Model

\section{Discussion and Conclusions}

This study focuses on the mechanism of inertia's influence on the willingness to explore the use of sports and fitness apps, in order to gain insight into what factors hinder users' exploration of the use of sports and fitness apps and to explore whether health goals have a moderating effect on status quo bias. Based on the status quo bias theory, this study proposes that inertia has a negative effect on the willingness to explore the use of sports and fitness apps, and introduces perceived need as a mediating variable from the perspective of attitude beliefs, and proposes that inertia influences the willingness to explore the use of sports and fitness apps through perceived need. Based on goal-setting theory, this study also notes that health goals have a moderating effect on each path of the mediator model. Three specific findings were identified as follows.

First, this study found that inertia negatively and significantly influenced the willingness to explore the use and perceived need for sports and fitness apps. Previous research on inertia has suggested that inertia plays a hindering role in behavioral transitions (Sun et al., 2017; Wang et al., 2018). In line with previous findings, this study pointed out that inertia has a hindering role in exploring the use of sports and fitness apps, i.e., mobile users are more inclined to stay in their current state and are not willing to explore the use of sports and fitness apps in order to improve their health status and gain more health benefits. Moreover, when users are in a state of status quo bias, their perceptions also tend to align with their current state and are reluctant to identify their health needs. Thus, inertia prevents mobile users from using sports and fitness apps for fitness exercise.

Second, this study found that perceived need positively and significantly influenced willingness to explore the use of sports and fitness apps, and that perceived need mediated the relationship between inertia and willingness to explore the use of sports and fitness apps. Previous research has argued that perceived need is not an influential factor in determining the initiation of physical activity and cannot account for physical activity intentions (Payne et al., 2004). In contrast to Payne et al.'s findings, this study verified that in perceived need had a positive effect on willingness to explore the use of exercise and fitness apps, suggesting that perceived need is a more salient belief for users to undertake mobile fitness exercise and can motivate them to explore exercise and 
fitness apps to undertake fitness exercise. This study is more consistent with related research on perceived usefulness in information systems, which suggests that perceived need predicts users' use of new information systems (Wang et al., 2018; Jeong et al., 2009). In addition, there is a new finding in this study that perceived demand has a mediating role. That is, when users are in a state of status quo bias, inertia negatively affects perceived demand and, in turn, a decreasing trend in perceived demand leads to a lower willingness to explore the use of exercise and fitness apps. This finding provides an explanation for a deeper understanding of users' exploratory use behavior.

Third, this study tested a research model of sports and fitness apps and found that health goals moderated the relationship between inertia and perceived need and that health goals also moderated the relationship between inertia and willingness to explore the use of exercise and fitness apps. In a related study of goals, Locket et al. (1991) concluded that high health goals stimulate a strong sense of self, which promotes better behavioral performance (Locke \& Latham, 2006; Dec \& Ryan, 2000). The findings of this study are consistent with Locket et al. in that high health goals attenuate the effects of inertia on users' beliefs (e.g., perceived needs), and intentions. In other words, when mobile users tend to maintain their old habitual state and are reluctant to use exercise and fitness apps for mobile fitness exercise, explicit health goals effectively adjust for inertia-induced biases. However, this study did not find a moderating effect of health goals on the relationship between perceived need and willingness to explore the use of the exercise and fitness app. One possible explanation is that when users have identified their health needs, health beliefs may be sufficient to motivate users to explore the relevant features of an exercise and fitness app (Wang et al., 2018; Jeong et al., 2009). Therefore, the moderating effect of health goals on the relationship between perceived needs and willingness to explore the use of exercise and fitness apps was not significant.

\section{Implications}

\subsection{Theoretical Implications}

First, this study extends the research of status quo bias theory in sports and fitness app exploratory use by developing a mediation model. Although scholars in the field of information systems have focused on users' exploratory use behavior and the ability of sports and fitness apps to provide new sports and fitness experiences and services to mobile users (Nambisan, Agarwal, \& Tanniru, 1999), few scholars have studied the exploratory use behavior of sports and fitness apps which are not quite active, and current research cannot explain what and how factors hinder users' exploratory use of sports and fitness. Based on the status quo bias theory, this study conducted an in-depth study on the exploratory use of sports and fitness apps (Samuelson \& Zeckhauser, 1988) and verified that inertia diminishes users' perceptions of health needs and that inertia diminishes users' willingness to explore the use of sports and fitness apps, revealing that inertia has a hindering effect on the exploratory use behavior of sports and fitness apps. Therefore, this study enriches the research of status quo bias theory in mobile app usage.

Second, this study extends the research of attitudinal beliefs in sports and fitness app use by introducing perceived need as a mediator in the research model. Previous research has suggested that attitudinal beliefs have an influential role on user behavior, using perceived need as a more salient belief for users to predict behavior (Wang et al., 2018; Jeong et al., 2009). However, Payne et al. (2004) did not find an influential role of perceived need on physical activity intentions. This study verified that perceived need positively influences willingness to explore the use of a sports and fitness app, and that perceived need mediates the relationship between inertia and intention to explore the use of a sports and fitness app, suggesting an essential role for perceived need in mobile fitness decisions. This study provides a new way of understanding how inertia affects sports and fitness apps exploration use and offers a new explanation for the existing literature's inconsistent findings on perceived need.

Finally, this study enriches the research on health goals in mobile fitness by exploring the moderating role of health goals as a moderating variable. Previous studies have examined goals in depth, exploring their effects on behavior and other aspects, suggesting that different goals lead to different cognitive and behavioral outcomes and that high goals evoke more motivation to act (Latham \& Locke, 1991; Bandura \& Cervone, 1986). However, studies have overlooked the moderating role of different levels of health goals in users' exploration of using a sports and fitness app in a mobile fitness scenario. This study introduced health goals as a moderating variable to explore the moderating effect of health goals on different paths in a mediated model of sports and fitness app exploration use, and verified the relationship between high health goal attenuation inertia on the willingness to explore sports and fitness app use and high health goal attenuation inertia on perceived need. This study reveals the impact that health goals can have on perceptions and behaviors in mobile fitness when adjusted for status quo bias with the intervention of awareness. From a positive perspective, this study suggests that health goals can 
help users overcome the effects of status quo bias when they are in a state of inertia. This study enriches the research on health goals in the use of sports and fitness apps by providing an understanding of different aspects of exploratory use behavior in sports and fitness apps.

\subsection{Practical Implications}

The results of this study carry several important practical implications. Firstly, multiple ways to evoke the health needs of users. Mobile fitness app companies should constantly innovate their marketing strategies to evoke users' health needs through different marketing approaches, so as to help users build up a new awareness of mobile fitness exercise and make them willing to try using sports and fitness apps for fitness exercise. For example, companies can integrate sports and fitness app with offline health promotion activities, and conduct mobile fitness promotion activities in campuses and communities. Through the popularization of mobile fitness, a strong mobile fitness culture can be created in the whole society. Under the influence of a strong mobile fitness atmosphere, users' health needs will be effectively aroused and a new awareness of mobile fitness will be established. Mobile fitness companies also should establish attractive mobile fitness communities to evoke users' health needs through fitness community influence and help them overcome the effects of status quo bias (Yang \& $\mathrm{Li}, 2016$ ). Previous research has concluded that community network relationships have a greater influence on users' perceptions and behaviors (Podolny \& Barson, 1997). When a friendly and interactive relationship is established between the sports and fitness app and users, the fitness community will subconsciously influence users' perceptions of mobile fitness exercise and thus carry out mobile fitness exercises. Moreover, sports and fitness apps should also encourage users to invite new users extensively, such as sending reward messages to invitees, or adding the function of users following each other, etc. (Rapp, Trainor, \& Agnihotri, 2010) to create a mobile fitness community with a high level of activity through various ways. Only by forming a good mobile fitness atmosphere can we continuously drive and arouse more users' mobile fitness needs, and thus effectively promote users' carrying out mobile fitness exercises.

Secondly, companies should play a considerable role in the use of health goals by users to better promote the widespread use of sports and fitness apps. To begin with, companies should provide a goal-setting function through which users can set their own health goals, and the goal-setting function should be dynamic in nature. Once users have established general health goals, they can also establish health sub-goals, i.e., break down health goals into smaller, implementable goals, such as setting long-term, medium-term, and short-term health goals, so that users can progressively engage in mobile fitness exercises (Papies, 2016). Companies should also provide users with appropriate fitness plans based on the goals set by users, taking into account their current level of health and propensity to exercise and fitness. It should also help users to adjust their health goals according to their current reality and promote goal-oriented mobile fitness exercise. Furthermore, companies should strengthen health management and service functions to remind users to stick to their exercise in a timely manner. Once a user has interrupted their mobile fitness exercise, information about the user's fitness status, such as what has been accomplished or what has not been accomplished, should be readily sent to the user to prompt them to continue their fitness exercise. Once the user has completed their health goals, the apps should encourage the user to set new health goals, thus keeping the user on the move for longer. In addition, companies also should encourage users to share their fitness goals in the fitness community. The different goals of fitness users can encourage users to set new goals to continue their mobile fitness workouts. Workable health goals can help users overcome the effects of status quo deviations to achieve more health benefits.

\section{Limitations and Recommendations}

There are some limitations to this study. First, this study focused on the different roles of health goals in the use of sports and fitness apps and did not consider other variables. Studies have discussed the influence of perceived advantages and sense of personal innovation on users' behavior when using new information technologies (Jeong et al., 2009; Huang, 2018). In future research, other factors such as perceived advantage, sense of self-innovation, subjective norms, personal achievement, and fun will be considered based on different theories and from different perspectives to further explore the effects of these factors on the use of sports and fitness apps and to expand the research on the use of sports and fitness apps to promote the widespread development of mobile sports and fitness activities. Secondly, the data in this study was only obtained from this questionnaire and not from other sources, such as watch bracelets, mobile phone manufacturers or sports and fitness app manufacturers. Future research will consider using multiple sources of data for this study, and will also consider designing questions about the identity of the respondents to compare and analyze the usage of users with different identities, in order to gain a deeper and more objective understanding of the usage behavior of users of sports and fitness apps. Finally, the development of mobile fitness activities is related to the social fitness movement culture and different countries have different mobile fitness movement profiles. This study is conducted in a Chinese context 
and may not be appropriate for other countries. Conducting a study on mobile fitness behavior in different countries, collecting data on the use of sports and fitness apps in different countries may obtain more interesting findings. Therefore, future research could be conducted cross-nationally to compare the similarities and differences in users' mobile fitness behaviors in different cultural contexts to enhance the generalizability of the study.

\section{References}

Analysys. (2020). July 2020 TOP1000 list of qianfan mobile App. Retrieved from https://www.analysys.cn/article/detail/20019888

Angosto, S., Garcia-Fernandez, J., Valantine, I., \& Grimaldi-puyana, M. (2020). The Intention to Use Fitness and Physical Activity Apps: A Systematic Review. Sustainability, 12, 1-24. https://doi.org/10.3390/su12166641

Bagozzi, R. P., \& Edwards, E. A. (1998). Goal setting and goal pursuit in the regulation of body weight. Psychology \& Health, 13(4), 593 -621.

Bandura, A., \& Cervone, D. (1986). Differential engagement of self-reactive cognitive motivation. Organizational behavior and human decision processes, 38, 92-113.

Bell, B. S., \& Kozlowski, S. W. (2002). Goal orientation and ability: Interactive effects on self-efficacy, performance, and knowledge. Journal of Applied Psychology, 87(3), 497-505. https://doi.org/10.1037/0021-9010.87.3.497

Cochran, G. W. (1977). Sampling Techniques (3rd ed.). New York, NY: John Wiley \& Sons.

Deci, E. L., \& Ryan, R. M. (2000). The "What" and "Why" of goal pursuits human needs and self-determination of behavior. Psychological Inquiry, 11(4), 227-268.

Downes, P. E., Kristof-Brown, A. L., Judge, T. A., \& Darnold, T. C. (2017). Motivational Mechanisms of Self-Concordance Theory: Goal-Specific Efficacy and Person-Organization Fit. Journal of Business \& Psychology, 32(2), 1-19. https://doi.org/10.1007/s10869-016-9444-y

Fornell, C., \& Larcker, D. F. (1981). Evaluating structural equation models with unobservable variables and measurement error. Journal of Mark. Research, 18, 39-50. https://doi.org/10.2307/3151312.

Fort, I., Jacquet, F., \& Leroy, N. (2011). Self-efficacy, goals, and job search behaviors. Career development international, 16(5), 469-481. https://doi.org/10.1108/13620431111168886.

Guo, Y., Bian, J., Leavitt, T., Vincent, K. H., Zalm, V. L., Teurlings, L. T., Smith, M. D., \& Modave, F. (2017). Assessing the Quality of Mobile Exercise Apps Based on the American College of Sports Medicine Guidelines: A Reliable and Valid Scoring Instrument. J Med Internet Res., 19(3), e67.

Hair, J. F., Anderson, R. E., Tatham, R. L., \& Black, W. C. (1995). Multivariate Data Analysis with Readings. Prentice-Hall, Engle wood Cliffs, NJ.

Hair, J. F., Hult, G. T. M., Ringle, C. M., \& Sarstedt, M. (2017). A Primer on Partial Least Squares Structural Equation Modeling (PLS-SEM). Sage Publications, Thousand Oaks, CA.

Huang, R. T. (2018). What motivates people to continuously post selfies? The moderating role of perceived relative advantage. Computers in Human Behavior, 80, 103-111. https://doi.org/10.1016/j.chb.2017.11.007.

Jeong, N., Yoo, Y., \& Heo, T.-Y. (2009). Moderating effect of personal innovativeness on mobile-RFID services: Based on Warshaw's purchase intention model. Technological Forecasting and Social Change, 76(1), 154-164. https://doi.org/10.1016/j.techfore.2008.08.007

Kim, H. W., \& Kankanhalli, A. (2009). Investigating user resistance to information systems implementation: A status quo bias perspective. MIS Quarterly, 33(3), 567-582. https://doi.org/10.2307/20650309.

Latham, G. P., \& Locke, E. A. (1991). Self-regulation through goal setting. Organizational behavior and human decision processes, 50, $212-247$.

Lee, T. W., Locke, E. A., \& Phan, S. H. (1997). Explaining the assigned goal -incentive interaction: The role of self-efficacy and personal goals. Journal of Management, 23(4), 541-559.

Lees, F. D., Clarkr, P. G., Nigg, C. R., \& Newman. P. (2005). Barriers to exercise behavior among older adults: A focus-group study. Journal of Aging and Physical Activity, 13, 23-33. https://doi.org/10.1123/japa.13.1.23

Li, M. Y. (2017). The Big Data Report on Family Health in China (2017). Retrieved from http://www.rmzxb.com.cn/c/2017-12-17/1902610.shtml 
Li, R., \& Li, J. (2017). A comparative study of National health strategies between China and the United States -based on the Outline of Healthy China 2030 and healthy Nation 2020. Journal of Nanjing University of Physical Education (Social Science Edition), 31(1), 42-47.

Locke, E. A. (1996). Motivation through conscious goal setting. Applied \&Preventive Psychology, 5, 117-124. https://doi.org/10.1016/S0962-1849(96)80005-9.

Locke, E. A., \& Latham, G. P. (2006). New directions in goal-setting theory. Current Directions in Psychological Science, 15(5), 265-268.

Locke, E. A., Frederick, E., Lee, C., \& Bobko, P. (1984). Effect of self -efficacy, goals, and task strategies on task performance. Journal of Applied Psychology, 69(2), 241-251.

Maslow, A. H. (1968). Toward a psychology of being. New York: Van Nostrand Reinhold.

Nambisan, S., Agarwal, R., \& Tanniru, M. (1999). Organizational mechanisms for enhancing user innovation in information technology. Mis Quarterly, 23(3), 365-395. https://doi.org/10.2307/249468.

Nunnally, J. C. (1978). Psychometric Theory 2nd. McGraw-Hill, New York.

Papies, E. K. (2016). Health goal priming as a situated intervention tool: How to benefit from nonconscious motivational routes to health behavior. Health Psychol Rev, 10(4), 408-424. https://doi.org/10.1080/17437199.2016.1183506.

Park, M., Yoo, H., Kim, J., \& Lee, J. M. (2018). Why do young people use fitness apps? Cognitive characteristics and app quality. Electronic Commerce Research, 18(4), 755-761. https://doi.org/10.1007/s10660-017-9282-7.

Payne, N., Jones, F., \& Harris, P. R. (2004). The role of perceived need within the theory of planned behavior: A comparison of exercise and healthy eating. British Journal of Health Psychology, 9, 489-504.

People.cn. (2021). China Mobile Internet Development Report (2021) has been officially released. Retrieved from http://finance.people.com.cn/GB/n1/2021/0722/c1004-32166880.html

Phillips, J. M., \& Gully, S. M. (1997). Role of goal orientation, ability, need for achievement, and locus of control in the self-efficacy and goal-setting process. Journal of Applied Psychology, 82(5), 792 -802.

Plaete, J., Bourdeaudhuij, I. D., Verloigne, M., \& Crombez, G. (2016). The use and evaluation of self-regulation techniques can predict health goal attainment in adults: An explorative study. PeerJ. 4(3), 1-21. https://doi.org/10.7717/peerj.1666.

Podolny, J. M., \& Baron, J. N. (1997). Resources and relationships: Social networks and mobility in the workplace. American Sociological Review, 62(5), 673-693. https://doi.org/10.2307/2657354.

Polites, G., \& Karahanna, E. (2012). Shackled to the Status Quo: The inhibiting effects of incumbent system habit, switching costs, and inertia on new system acceptance. MIS Quarterly, 36(1), 21-42.

Rapp, A., Trainor, K. J., \& Agnihotri, R. (2010). Performance implications of customer-linking capabilities: Examining the complementary role of customer orientation and CRM technology. Journal of Business Research, 63(11), 1229-1236. https://doi.org/10.1016/j.jbusres.2009.11.002

Samuelson, W., \& Zeckhauser, R. (1988). Status quo bias in decision-making. Journal of Risk \& Uncertainty, l(1), 7-59.

Sebire, S. J., Standage, M., \& Vansteenkiste, M. (2011). Predicting objectively assessed physical activity from the content and regulation of exercise goals: Evidence for a mediational model. Journal of Sport \& Exercise Psychology, 33, 175-197. https://doi.org/10.1123/jsep.33.2.175

Strecher, V. J., Seijts, G. H., Kok, G. J., Latham, G. P., Glasgow, R., DeVellis, B., Meertens, R. M., \& Bulger, D. W. (1995). Goal setting as a strategy for health behavior change. Health Education Quarterly, 22(2), 190-200. https://doi.org/10.1177/109019819502200207

Sun, Y. Q., Liu, D., Chen, S. J., Wu, X. R., Shen, X. L., \& Zhang, X. (2017). Understanding users' switching behavior of mobile instant messaging applications: An empirical study from the perspective of push-pull

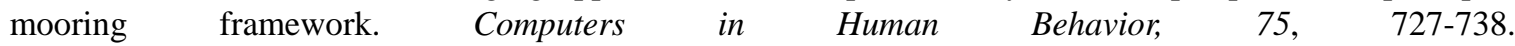
https://doi.org/10.1016/j.chb.2017.06.014

Teng, W., Lu, H. P., \& Yu, H. (2009). Exploring the mass adoption of third-generation (3G) mobile phones in Taiwan. Telecommunications Policy, 33(10-11), 628-641. 
Vähäsarja, K., Salmela, S., Villberg, J., Rintala, P., Vanhala, M., Saaristo, T., ... Poskiparta, M. (2012). Perceived need to increase physical activity levels among adults at high risk of type 2 diabetes. A cross-sectional analysis within a community-based diabetes prevention project FIN-D2D. BMC Public Health, 12(514), 1-10. https://doi.org/10.1186/1471-2458-12-514

Vance, R. J., \& Colella, A. (1990). Effects of two types of feedback on goal acceptance and personal goals. Journal of Applied Psychology, 75(1), 68-76. https://doi.org/10.1037/0021-9010.75.1.68

Venkatesh, V., \& Morris, M. G. (2003). User acceptance of information technology: Toward a unified view. MIS Quarterly, 27(3), $425-478$.

Wang, Y. Y., Wang, Y. S., \& Lin, T. C. (2018). Developing and validating a technology upgrade model. $\begin{array}{lllll}\text { International Journal of Information } & \text { Management, } & 38(1), & \text { 7-26. }\end{array}$ https://doi.org/10.1016/j.ijinfomgt.2017.07.003

Yang, X., \& Li, G. (2016). Factors influencing the popularity of customer-generated content in a company-hosted online co-creation community: A social capital perspective. Computers in Human Behavior, 64, 760-768.

Yuan, S. P., Ma, W. J., Kanthawala, S., \& Peng, W. (2015). Keep Using My Health Apps: Discover Users' Perception of Health and Fitness Apps with the UTAUT2 Model. Telemedicine and e-Health, 21(9), 735-741. https://doi.org/10.1089/tmj.2014.0148

Zhang, X. F. (2014). Research on the Hindrance factors of online medical service adoption based on the Theory of status quo Deviation. Dissertation. Harbin: Harbin Institute of Technology.

\section{Copyrights}

Copyright for this article is retained by the author(s), with first publication rights granted to the journal.

This is an open-access article distributed under the terms and conditions of the Creative Commons Attribution license (http://creativecommons.org/licenses/by/4.0/). 